\title{
Depression and pegylated interferon-based hepatitis $C$ treatment
}

This article was published in the following Dove Press journal:

International Journal of Interferon, Cytokine and Mediator Research

27 March 2012

Number of times this article has been viewed

\author{
Haris Papafragkakis' \\ Murali S Rao ${ }^{2}$ \\ Martin Moehlen ${ }^{3}$ \\ Sonu Dhillon ${ }^{4}$ \\ Paul Martin' \\ 'Division of Hepatology, University \\ of Miami Miller School of Medicine, \\ Miami, FL, ${ }^{2}$ Department of Psychiatry \\ and Behavioral Neurosciences, Loyola \\ University Medical Center, Maywood, \\ IL, ${ }^{3}$ Division of Gastroenterology \\ and Hepatology, Tulane University, \\ New Orleans, LA, ${ }^{4}$ Division of \\ Gastroenterology and Hepatology, \\ St Francis Medical Center, \\ Peoria, IL, USA
}

\begin{abstract}
Interferon remains an essential component of treatment regimens for chronic hepatitis $\mathrm{C}$ infection. Mood disturbances, including depression, are relatively common in the hepatitis $\mathrm{C}$ virus-infected population and may worsen during hepatitis $\mathrm{C}$ treatment. Screening for depression prior to commencement of therapy is crucial and may improve treatment outcomes. Whether prophylactic antidepressant therapy should be initiated prior to therapy of hepatitis C virus infection with an interferon-based regimen remains unclear. We review the epidemiology, diagnosis, and management of depression before and during treatment of hepatitis $\mathrm{C}$ virus infection with interferon.
\end{abstract}

Keywords: pegylated interferon, hepatitis C, depression, suicide risk, cytokines

\section{Introduction}

Hepatitis $\mathrm{C}$ virus (HCV) is the most common chronic blood-borne infection in the United States. At least 4 million people have been exposed and 3.2 million are chronic carriers of the disease. ${ }^{1}$ However, that number may possibly be higher if we consider the homeless (usually with no access to care), prisoners, illegal immigrants, and people who are unaware of their disease status and do not seek medical attention. The World Health Organization estimates that about 180 million people are infected worldwide and more than 350,000 die from hepatitis C-related liver disease each year. ${ }^{2}$ The treatment paradigm for HCV has changed with the recent Food and Drug Administration approval of two first generation protease inhibitors, telaprevir, and boceprevir for genotype 1 infected individuals. Nonetheless, ribavirin and pegylated interferon (Peg-IFN) remain integral components of treatment. It is anticipated that Peg-IFN will remain part of the HCV treatment, thus management of its side effects is essential. One of the well-established side effects of interferon (IFN) is depressive mood of variable severity, including suicidal ideation, which often leads to discontinuation of therapy. Our review focuses on the diagnosis and management of depression before and during treatment of $\mathrm{HCV}$ infection with IFN. We briefly discuss the development of depression in relation to cytokines and the role of serotonin and kynurenine in the pathogenesis of depression during IFN therapy. We also discuss the prevalence of depression in HCV patients treated with various IFNbased regimens and also studies evaluating the role of antidepressants in preventing or ameliorating depression during treatment of chronic hepatitis $\mathrm{C}$ infection.

\section{Role of IFN in the pathogenesis of depression}

IFNs are naturally occurring host proteins which are produced by activated macrophages and lymphocytes in response to a viral insult. The first cytokines identified were the 
IFN types I and II. IFN- $\alpha$ is a type I IFN and belongs to the same group as the IFN- $\beta, \kappa, \omega, \delta$, and $\tau$. IFN- $\gamma$ is a type II IFN. Recently a third member of this group of cytokines has been identified and has been termed IFN- $\lambda$. $^{3}$ The three members of this newly identified cytokine family are IFN- $\lambda 1$, IFN- $\lambda 2$, and IFN- $\lambda 3$ or interleukins (IL) IL-28 A, IL-28B, and IL-29. ${ }^{4,5}$ Cytokines are large polypeptide mediators that regulate cellular growth, differentiation, and function. ${ }^{6}$ The pro-inflammatory cytokines, including IL-1, IL-6, and tumor necrosis factor, stimulate the immune system to act at a site of cell injury. In contrast, the anti-inflammatory cytokines, such as IL-10 and IL-13, suppress the immune response and halt the production of pro-inflammatory cytokines. ${ }^{7}$

The pathogenesis of depression in HCV patients treated with IFN-based regimens is felt to be multifactorial and several mechanisms have been identified. Recently the molecular mechanisms and involved mediators responsible for depression have been better characterized. ${ }^{8}$ This research suggests that depression represents overexpression of pro-inflammatory cytokines along with hypersecretion of glucocorticoids. This probably reflects a downregulation of glucocorticoid receptors on immune cells and subsequent failure of glucocorticoids to suppress the cellular immune system. These receptors return to a normal level of function in patients who undergo treatment for depression. ${ }^{9}$

The development of depression seems to be primarily induced by serotonin metabolism dysregulation. IFN- $\alpha$, IFN- $\gamma$, and IL-1 upregulate a serotonin transport protein and cause a reduction in extracellular 5-hydroxytryptamine levels, ${ }^{10}$ whereas IFN- $\alpha$ may modulate serotonin receptors in the brain. ${ }^{11,12}$ Cytokines have been shown to upregulate indoleamine 2,3 deoxygenase production and cause depression through a reduction in the production of central serotonin. ${ }^{13}$ Genetic differences in the serotonin re-uptake transporter promoter, especially the short/short genotype, may increase the frequency of depression during Peg-IFN and ribavirin treatment, as shown in a study of $78 \mathrm{HCV}$ infected individuals. No differences were observed in Caucasians compared to African Americans. ${ }^{14}$ IFN- $\alpha$ causes a decrease in tryptophane (TRP) approximately 4-6 months after initiation of treatment and an increase in kynurenine at 2 weeks. ${ }^{15}$ Additionally, it has been found that IFN- $\alpha$ can lead to the production of multiple neuroactive metabolites. These metabolites affect the kynurenine/TRP ratio which has been associated with depression. ${ }^{16}$ Furthermore, these metabolites have been found to be toxic in animal studies, ${ }^{17}$ in vitro, ${ }^{18}$ and may play a role in depression, ${ }^{19}$ anxiety, ${ }^{20}$ and schizophrenia. ${ }^{21}$ Overproduction of reactive oxygen species, such as superoxide radical, hydrogen peroxide, and hydroxyl radical, have also been related to the development of depression. ${ }^{18}$ Increased pro-inflammatory cytokines, enhanced monoamine oxidase inhibitor activity, increased free radicals, low levels of catecholamines, and reduction in serotonin and catecholamine receptor densities, have all been implicated in the development of depression. ${ }^{22-25}$ Additionally, it has been reported that IFN- $\alpha$ suppresses the levels of serum dipeptidyl peptidase IV in 2-4 weeks and even more so after 16-24 weeks of IFN treatment. ${ }^{26}$ Serum dipeptidyl peptidase IV is a membrane bound serine that plays a role in modulation of T-cell activity. Its suppression during IFN- $\alpha$ therapy has been associated with higher Montgomery-Asberg Depression Rating Scale and Hamilton Anxiety Scale scores, an increase in the kynurenine/TRP quotient and IL-8 in the serum, leading to intensification of depressive symptomatology. In a recent study, $\mathrm{HCV}$ treatment with IFN $\alpha-2 \mathrm{a}$ or $2 \mathrm{~b}$ plus ribavirin was associated with total serum TRP reduction after 1 month and 6 months, primarily related to a reduction in the albumin-bound TRP molecule, with no significant differences observed between males and females. Normalization of TRP levels occurred 3 months after the end of treatment. The levels of kynurenine rose while on IFN treatment and the indoleamine 2,3 deoxygenase activity was enhanced. ${ }^{27}$ Normalization of TRP and kynurenine levels 6 months to a year after completion of HCV therapy has been associated with a significant decrease in the incidence of depression and most likely post-treatment suicide risk. ${ }^{28,29}$

\section{Hepatitis C treatment and depression}

IFN and ribavirin remain the backbone of $\mathrm{HCV}$ treatment. While typically given daily or thrice weekly, a pegylated form is administered weekly. This weekly dosing has been found to result in less disabling fatigue, with fewer reports of myalgias and arthralgias. This less toxic preparation in turn has caused decreased reports of depression during treatment with Peg-IFN compared to standard IFN. ${ }^{30}$ Additionally, use of Peg-IFN $\alpha-2 b$ has been associated with better quality of life compared to the use of standard IFN $\alpha-2 b .{ }^{31}$ While one study showed that depression, hostility, and anger did not decrease significantly with the use of Peg-IFNs, ${ }^{32}$ another trial demonstrated that patients treated with Peg-IFN $\alpha-2 \mathrm{a}$ at a standard dose of $180 \mu \mathrm{g}$ per week plus ribavirin had significantly less depression compared to those treated with standard IFN plus ribavirin and had delayed presentation of depressive symptoms, occurring usually after the week 12 of therapy. ${ }^{33}$ Manns et al demonstrated that the use of Peg-IFN $\alpha-2$ a plus ribavirin 
was associated with similar frequency of adverse events compared to standard IFN plus ribavirin (31\% depression, 35\% irritable behavior, and $40 \%$ sleep disturbances). ${ }^{34}$ Consensus IFN, an artificial $\alpha$-IFN, has similar characteristics as naturally occurring IFNs with respect to depression. ${ }^{35-38}$

Depression in HCV-infected individuals occurs in up to $60 \%, 39,40$ however, depression itself is not a contraindication to HCV treatment. Depression, along with lower socioeconomic status, remains a significant barrier to those seeking treatment for $\mathrm{HCV}$ in its early stages, ${ }^{41}$ suggesting that proper screening and treatment of depression in HCV patients by the primary care physician may increase their attendance to gastroenterology and hepatology clinics for evaluation and treatment of hepatitis $\mathrm{C}$ with improved response rates and reduction of the eventual complications of the disease, mainly cirrhosis and hepatocellular carcinoma.

\section{Screening for depression}

During HCV treatment with IFN-based regimens the prevalence of depression has been reported to be between $10 \%-40 \%$ depending on the screening method used. ${ }^{39}$ Several methods have been developed to assess and follow depression in patients with hepatitis C. The Center for Epidemiological Studies Depression Scale may be helpful in screening patients prior to the initiation of IFN therapy and at regular intervals thereafter for the presence of depression. ${ }^{42} \mathrm{~A}$ score above or equal to 16 , or expression of suicidal ideation should be an indication for psychiatric consultation. ${ }^{43}$ In a recent single-center study of veterans with chronic HCV infection randomized to either the Center for Epidemiological Studies Depression Scale questionnaire (using a cut-off of 14 for depression) or single-standardized question by the treating physician, there was no difference in compliance and sustained virological response (SVR) rates between the two groups ${ }^{44}$ Another study used a different screening method, the Cornell Medical Index, and suggested that it could be used prior to IFN therapy to predict the occurrence of depressive symptoms. ${ }^{45}$

Other screening modalities that have been used for evaluation of depression are the Hamilton Depression Rating Scale, the Montgomery-Asberg Depression Rating Scale, and the Beck Depression Inventory (BDI-I and II, Table 1). In a study of 39 patients, those found to have developed severe depression during IFN therapy had baseline BDI scores significantly higher than those without severe depression. ${ }^{46}$ Additionally, patients with more symptoms of depression prior to the initiation of IFN therapy had a higher risk of IFN induced depression as compared to patients with
Table I Depression according to BDI, BDI-II, MDI and CES-D scoring systems

\begin{tabular}{ll}
\hline Beck depression inventory (BDI) & $<15$ \\
Mild & 15 to 30 \\
Moderate & $>30$ \\
Severe & \\
BDI-II & 0 to 13 \\
Minimal & 14 to 19 \\
Mild & 20 to 28 \\
Moderate & 29 to 63 \\
$\quad$ Severe & \\
Major depression inventory (MDI) & $>26$ \\
$\quad$ Moderate to severe & \\
Center for epidemiological studies depression & \\
scale (CES-D) & $>16$ \\
Depression, consideration for psychiatric evaluation &
\end{tabular}

few or no depressive symptoms prior to therapy. In the same study it was shown that more than $50 \%$ of the patients who developed depression did so during or after the 12th week of treatment. The vast majority of them responded well to treatment with citalopram and had a decrease in BDI score by $50 \%$ in $5-6$ weeks, with remission occurring on average after 9 weeks of therapy. The majority of the patients who developed depression manifested an increase in the BDI score from 10 or less to 18 or more in 2 weeks. This observation lends support to the practice of sequentially screening for IFN-induced depression at 2 week intervals. A recent study of 211 previously untreated patients, without history of depression and substance abuse, demonstrated the potential effectiveness of a multidisciplinary approach in reducing the incidence of depression and other psychiatric disturbances during hepatitis $\mathrm{C}$ treatment. In particular, monthly evaluation of the patients by a psychiatrist was associated with less depression, psychosis, and delirium compared to an "as needed" approach. In that study more patients developed severe psychiatric symptoms between the 24th and 36th week of therapy, but there was no difference in SVR rates between the groups studied. This may suggest that a more frequent psychiatric evaluation of patients with $\mathrm{HCV}$ undergoing treatment may dramatically decrease the rate and severity of depression and other mood disturbances, and likely increase compliance and decrease dropout rates. ${ }^{47}$ The HALT-C trial studied $201 \mathrm{HCV}$ patients with no recent history of severe psychiatric condition and used the Composite International Diagnostic Interview instrument and the BDI-II questionnaire to assess the presence of depression. The incidence of depression was $23 \%$ at week 24 and $48 \%$ at week 48 of treatment with Peg-IFN $\alpha-2 a$ and ribavirin, with absence of virological response at week 20 being the only independent predictor 
of depression by week 24 of treatment. In the same study cortisol levels remained essentially unchanged during treatment and were not associated with depression. ${ }^{48}$ Additionally, low dose maintenance Peg-IFN ( $90 \mu \mathrm{g} /$ week) for 3.5 years in previous non-responders to standard treatment did not result in an increased incidence of depression. ${ }^{49}$

Another screening test for depression during $\mathrm{HCV}$ treatment, the Major Depression Inventory, was studied in $325 \mathrm{HCV}$-infected patients and was shown to be useful in diagnosing depression in the outpatient setting, particularly when a psychiatrist or psychologist is not readily available to facilitate the diagnosis. In the study $6 \%$ had major depression before treatment, as indicated by a Major Depression Inventory score $>35$ and $35 \%$ developed major depression during therapy. In accordance with other studies, the majority developed depression during the first 12 weeks of treatment. Women had higher prevalence of depression and were treated more often than men. Discontinuation rates were higher in depressed patients who remained untreated. One other notable finding in that study was that depression was associated with fatigue in $70 \%$ and sleep disturbances in $90 \%$ of the patients. ${ }^{50}$

\section{Treatment related depression}

Recently, data from the Virahep-C study, a prospective analysis of depression during HCV genotype 1 treatment with Peg-IFN and ribavirin, demonstrated that low social support was independently associated with pre-treatment and on-treatment development of depression. ${ }^{51}$ In an almost equal number of African Americans and Caucasians it was demonstrated that pre-treatment depression rates were similar. At any time during the study $20 \%$ had depressive symptoms whereas $18 \%$ of non-responders compared to $10 \%$ of responders had depression 6 months after the end of treatment, a difference that may be explained by the failure of a challenging 48-week treatment course. During treatment $21 \%$ of patients developed depression during the first 12 weeks. Higher discontinuation rates were noted in patients with pre-treatment depression compared to those with no baseline depression. Null or partial response to treatment and subsequent discontinuation was less frequent in subjects with newly developed depression during treatment compared to those who did not develop depression. This interesting observation may imply that patients with newly diagnosed depression during IFN treatment were managed appropriately upon initiation of symptoms and were likely very motivated to treat their depression and continue $\mathrm{HCV}$ treatment. This observation may also suggest that the more robust the immune response the higher the depression rates are. Interestingly, compliance in both groups was similar and as a result the SVR rates were not statistically different between patients who developed depression during treatment compared with those who did not (47\% vs 38\%). Depression data between weeks 24 and 48 were not analyzed because of discontinuation of treatment in non-responders (detectable HCV by week 24) according to the study protocol.

Recently the presence of the C/C allele in the IL-28B polymorphism of the host has been associated with much better response to IFN and ribavirin in genotype $1 \mathrm{HCV}$ infected patients compared to carriers of the $\mathrm{C} / \mathrm{T}$ or $\mathrm{T} / \mathrm{T}$ alleles. ${ }^{52} \mathrm{In}$ a prospective study of 133 patients with IL-28B polymorphism the T/T genotype was associated with less appetite, energy, and sleep complaints during hepatitis $\mathrm{C}$ treatment with Peg-IFN $\alpha$. Patients with T/T developed anorexia less frequently (3.1\%) compared to $10.1 \%$ of those with the $\mathrm{C} / \mathrm{T}$ and $8.9 \%$ with the $\mathrm{C} / \mathrm{C}$ genotype. Major sleep problems were present in $10.8 \%$ with the $\mathrm{T} / \mathrm{T}$ genotype, compared to $16.1 \%$ with the $\mathrm{C} / \mathrm{T}$ and $20.7 \%$ with the $\mathrm{C} / \mathrm{C}$ genotype. IL-28B genotype did not predict the development of major depression. The $\mathrm{C}$ allele was associated with better clearance of $\mathrm{HCV}$ during IFN-based treatment; however, with more frequent appetite, energy, and sleep complaints. The results of this study suggest that patients with the favorable IL-28B allele may develop more somatic complaints during IFN treatment, despite no clear association between the $\mathrm{C} / \mathrm{C}$ genotype and the development of severe depression. It appears that the presence of the $\mathrm{C}$ allele is related to a more robust immune response to IFN treatment and as such these patients express more adverse psychological events. More studies are needed to elucidate this association further. ${ }^{53}$

\section{Suicide risk and IFN for HCV treatment}

One of the main concerns in HCV treatment candidates with depression is the potential risk of suicide, especially since many of these patients suffer from concomitant depression prior to initiation of therapy. A recent study of $1010 \mathrm{HCV}$ infected patients demonstrated that suicide risk was higher in males and in patients under the age of $45 .{ }^{54}$ Sporadic cases of suicidal ideation during IFN treatment for HCV have been reported in the literature. In one case a patient on standard IFN thrice weekly developed symptoms of anxiety, sleep disturbances, guilt feelings, and problems at work culminating in suicidal ideation and urgent hospital admission. ${ }^{55}$ Suicidal ideation with delusions and insomnia in a patient on Peg-IFN and ribavirin has also been reported, with symptoms presenting 
late in a 24-week treatment course (22nd week) and even shortly after its discontinuation. ${ }^{56}$ In a study of 42 patients on standard IFN 17\% had suicidal ideation prior to treatment, which increased to $26 \%$ after starting therapy. All these patients underwent psychiatric evaluation and most completed a 6-month treatment course with no suicide adverse events. ${ }^{57}$ Different conclusions were reached in a study of almost $400 \mathrm{HCV}$-infected patients with genotype 1 on Peg-IFN and ribavirin, where just 3.5\% reported suicidal ideation and none attempted suicide. ${ }^{51}$ Elsewhere in the literature, many $\mathrm{HCV}$ treatment studies have reported various depression and suicidal ideation rates, making the application of these results to clinical practice impractical. This inconsistency in reporting may reflect the utilization of different depression screening methods, physician and patient biases in diagnosing and reporting symptoms, and variable treatment protocols followed. Table 2 summarizes important studies and their reported depression and suicidal ideation rates. Overall, suicide risk during $\mathrm{HCV}$ treatment should always be considered and suicidal ideation being a known risk factor of IFN therapy should be discussed with the patients and their families prior to commencement of therapy. Patients with personal or family history of a serious mood disorder, depression, suicidal ideation or attempt, as well as drug or alcohol abuse should be carefully interviewed and referred to a specialist for assessment of suicide risk and treatment of the underlying disorder before treatment with IFN can be considered.

\section{Prevention and treatment of IFN-induced depression}

Patients with a history of severe depression or those taking antidepressants should be evaluated by a psychiatrist prior to HCV treatment. An observational study of $20 \mathrm{HCV}$ genotype 2 or 3 patients demonstrated that patients with prior depression who were not on an antidepressant at the beginning of $\mathrm{HCV}$ therapy were more likely to drop out and achieved a lower SVR than HCV patients on antidepressants at the beginning of treatment. ${ }^{58}$ Selective serotonin re-uptake inhibitors (SSRIs) have been shown to be effective in treating depression in IFN-treated patients. ${ }^{59}$ In a study of 15 patients treated with citalopram, $87 \%$ responded well to the medication with no change in liver function tests when $10-40 \mathrm{mg} /$ day of the drug was used.$^{60}$ In a more recent randomized, double-blind, placebo-controlled study, citalopram was shown to be an excellent treatment option for patients who developed depression during treatment with IFN for $\mathrm{HCV}$ compared to placebo. Interestingly and contrary to other reports, patients who developed depression during treatment had a trend towards a lower percentage of SVR compared to those without depression. ${ }^{61}$ Recently the effectiveness of prophylactic antidepressants has been questioned. A randomized, double-blind, placebo-controlled trial on the efficacy of citalopram to prevent depression in $\mathrm{HCV}$ patients when given 2 weeks prior to the commencement of Peg-IFN and ribavirin treatment failed to demonstrate benefit of the drug compared to placebo. The incidence of depression was only $15.4 \%$ in the 39 patients studied. Studies with higher power and more rigorous inclusion criteria are needed to establish the role of SSRIs in prevention of depression. ${ }^{62}$

Prophylactic administration of paroxetine, another SSRI, 2 weeks prior to IFN-based therapy was associated with a significantly reduced rate of major depression and a discontinuation rate of IFN treatment of only 5\% compared to $35 \%$ in the placebo group. ${ }^{63}$ Paroxetine prophylaxis was studied in a randomized double-blind, placebo-controlled trial and demonstrated that when given 2 weeks prior to treatment at a starting dose of $10 \mathrm{mg} / \mathrm{d}$ may lead to less severe depression during HCV treatment compared to placebo. That study supports a beneficial role of SSRI prophylaxis prior to HCV treatment. Interestingly, paroxetine reduced muscle and joint pain in the population studied, which are common symptoms of IFN therapy, but caused more dizziness than in the placebo group. ${ }^{64}$ Other common side effects of SSRIs may include headache, sexual dysfunction, anxiety, gastrointestinal upset, and diaphoresis. ${ }^{65}$ Paroxetine and citalopram were studied in a placebo-controlled trial for prevention of depression in patients previously treated with standard IFN. This study showed that re-treatment with Peg-IFN and ribavirin is safe in patients with prior in-treatment depression, when a 3-week SSRI prophylaxis protocol is implemented ${ }^{66,67}$ Another SSRI, escitalopram, was evaluated in a randomized, double-blind, placebo-controlled trial for its role in preventing depression in $\mathrm{HCV}$ patients without prior depression within the first 12 weeks of standard HCV treatment. In contrast to other reports, it did not result in less depression compared to placebo; however, a longer follow-up may have yielded different results, since other studies have demonstrated peak of depression after the 12 th week of treatment. ${ }^{68}$ Milnacipran, a serotonin and norepinephrine re-uptake inhibitor (SNRI), was studied in elderly depressed patients on IFN and was found to be efficacious with no incidence of anticholinergic or other side effects. ${ }^{69}$ Of note, the use of tricyclic antidepressants probably should be avoided, because of increased sedation and worsened cognition, potentiation of the side effects of IFN, and possible cardiotoxicity. ${ }^{70}$ Other agents that can be used include bupropion, mirtazapine, and venlafaxine. In the 


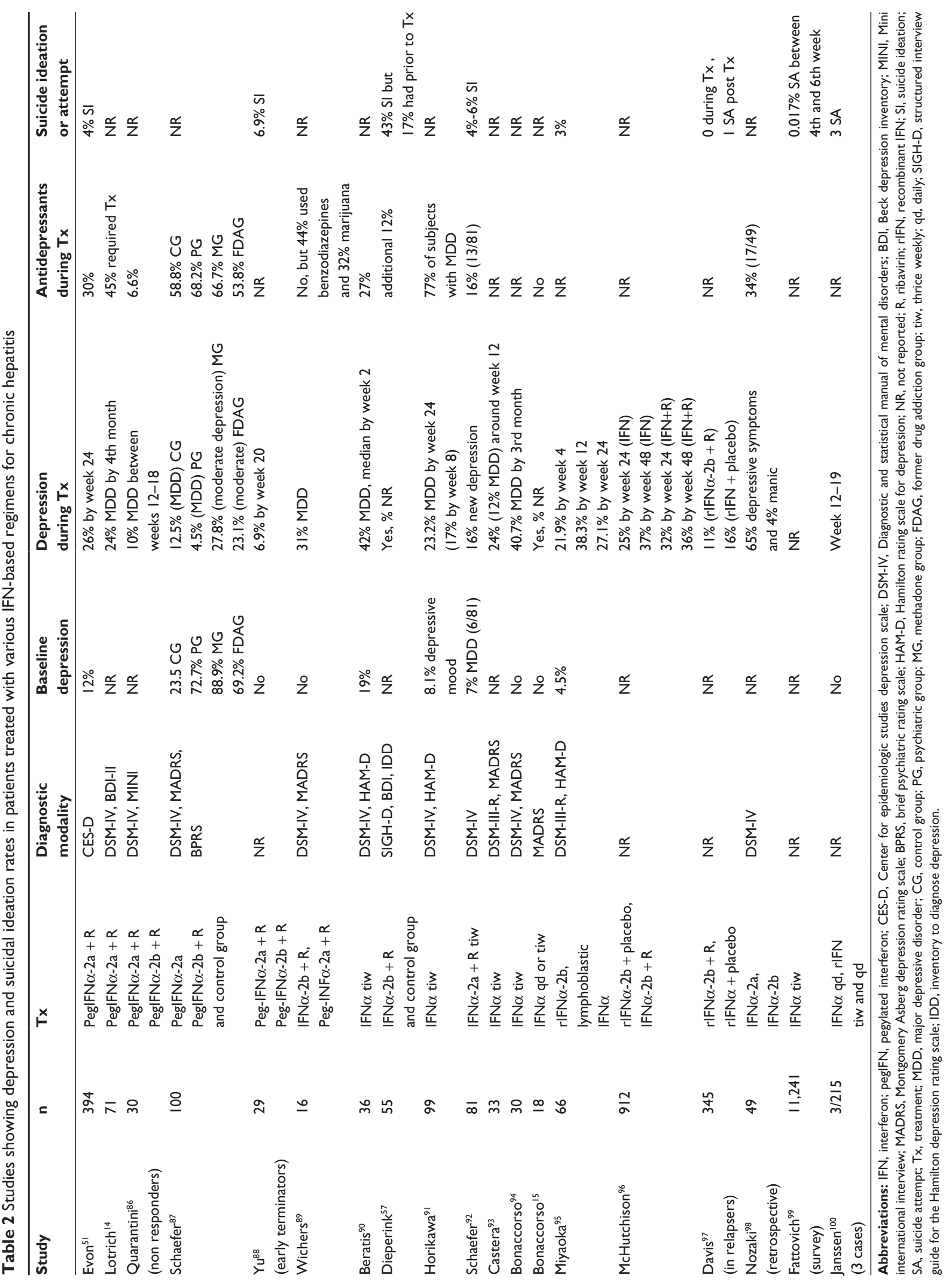


case of refractory depression the addition of psychostimulants, such as methylphenidate or dextroamphetamine, may be of benefit. ${ }^{71}$

Depressive symptoms may persist even after 6 months after the discontinuation of $\mathrm{HCV}$ treatment; however, the optimal duration of antidepressant use after completion of $\mathrm{HCV}$ therapy remains unclear. It has been suggested that it should be continued for approximately 3-6 months to ameliorate the risk of depression relapse post-treatment. ${ }^{72-74}$ A suggested algorithm for the management of $\mathrm{HCV}$ patients with depression is shown in Figure 1. The diagnostic criteria for depression, mania, and hypomania listed in Table 3 may be helpful in guiding the physician towards the correct diagnosis, but they require careful interpretation and often psychiatric referral.

Special attention should be paid to those individuals who, while on treatment, present with signs of mania. A study by Gould et al demonstrated that mania may be present in
$20 \%$ of patients while on Peg-IFN and ribavirin. ${ }^{75}$ While irritability is uncommonly seen in patients on IFN-based therapy, the development of euphoria, a hallmark of mania, is virtually diagnostic. These cases may be challenging because SSRI use can potentially exacerbate the clinical condition. Nonetheless, irritability may be part of a depressive presentation when other signs of depression are present as well. The use of an SSRI in these cases is reasonable.

A diagnosis or prior history of schizophrenia and schizoaffective disorder necessitates psychiatric evaluation prior to IFN-based treatment. Huckans et al reported that 30 patients with history of schizophrenia received treatment for HCV and had similar rates of psychiatric symptoms compared to an untreated cohort. However, the rate of achieved SVR was lower in the schizophrenic group who developed depression compared to the group without depression during HCV treatment $(20 \%$ vs $70 \%) .{ }^{76}$ Although this was a retrospective study with a small sample size and other limitations, it may suggest

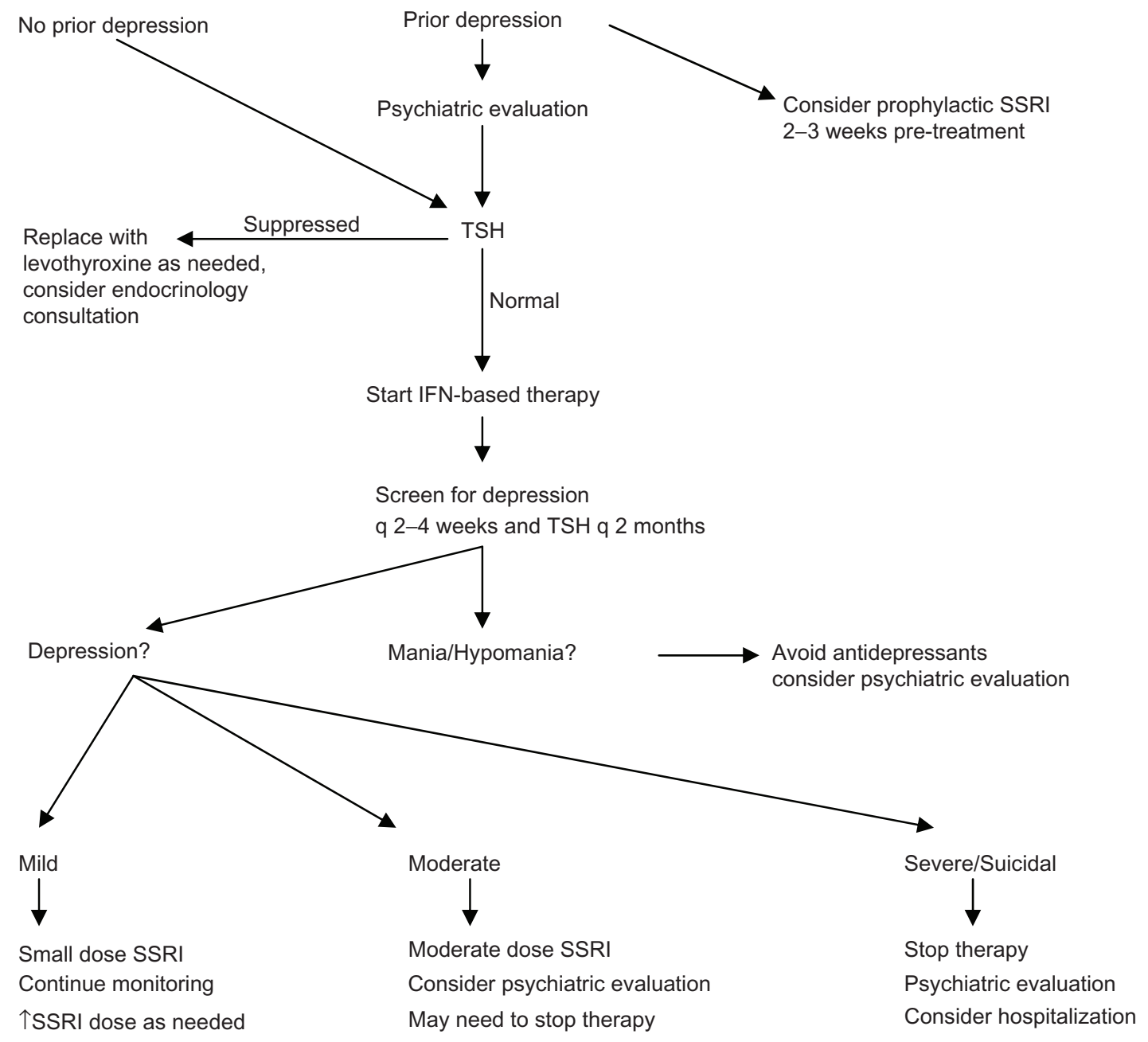

Figure I Proposed algorithm for the management of the HCV patient with depression prior to or during IFN treatment. Abbreviations: SSRI, selective serotonin re-uptake inhibitor; TSH, thyroid-stimulating hormone; IFN, interferon; HCV, hepatitis C virus. 
Table 3 Criteria for diagnosis of depression, hypomania and mania

\begin{tabular}{|c|c|c|}
\hline Depression & Hypomania & Mania \\
\hline $\begin{array}{l}\text { Minor depression: at least } 2 \text { and less than } 5 \text {. } \\
\text { At least one of them is A or B }\end{array}$ & $\begin{array}{l}\text { Persistently elevated mood, } \\
\text { irritability }>4 \text { days }\end{array}$ & $\begin{array}{l}\text { Persistently elevated mood, } \\
\text { irritability }>\text { I week }\end{array}$ \\
\hline \multicolumn{3}{|l|}{$\begin{array}{l}\text { Severe depression: more than } 5 \text {. At least one } \\
\text { of them must be }(A) \text { or }(B)\end{array}$} \\
\hline Sad mood, tearfulness $(A)$ & \multicolumn{2}{|l|}{ And 3 or more of the following } \\
\hline No interest or pleasure in almost all activities (B) & \multirow{2}{*}{\multicolumn{2}{|c|}{$\begin{array}{l}\text { Grandiosity, increased social activ } \\
\text { flight of ideas, easy distractibility }\end{array}$}} \\
\hline Weight and appetite changes & & \\
\hline \multicolumn{3}{|l|}{ Sleep disturbances, fatigue } \\
\hline Agitation or retardation observed by others & And the following criteria & \\
\hline $\begin{array}{l}\text { Feeling of worthlessness or guilt, altered } \\
\text { cognition }\end{array}$ & $\begin{array}{l}\text { No serious work problems, no psychosis, } \\
\text { Mood changes observed by others }\end{array}$ & $\begin{array}{l}\text { Impaired social and work function, } \\
\text { need for hospitalization, psychosis }\end{array}$ \\
\hline And the following criteria & Exclude hypothyroidism, other drug use & \\
\hline \multicolumn{3}{|l|}{ Social and work problems, } \\
\hline \multicolumn{3}{|l|}{ Thoughts of death, recurrent suicidal ideation } \\
\hline Exclude bereavement, hypothyroidism, other drug use & & \\
\hline
\end{tabular}

Note: Based on the Diagnostic and Statistical Manual of Mental Disorders, DSM-IV.

that close psychiatric evaluation and follow-up of schizophrenic patients during HCV treatment may yield good outcomes and that such patients should not be "a priori" excluded from HCV therapy once their disease is controlled.

Finally, it is important to acknowledge the effect of IFN on the thyroid and the potential development of depressive-like symptoms related to thyroid dysfunction, mimicking, or even masking depressive symptoms related to IFN use. Thyroid abnormalities have been observed in about $15 \%$ of individuals treated with IFN- $\alpha$ for hepatitis C. ${ }^{77,78}$ Hypothyroidism in particular has been reported in $2.4 \%$ to $19 \%$ of patients treated with IFN- $\alpha .{ }^{79,80}$ In a recent retrospective study of $288 \mathrm{HCV}$ patients, IFNinduced hypothyroidism was found in $11.9 \%$, with $1.5 \%$ requiring levothyroxine administration. ${ }^{81}$ Individuals with detectable thyroid autoantibodies before initiation of IFN- $\alpha$ treatment are more likely to develop thyroid dysfunction, although elevated thyroid-stimulating hormone was more sensitive than thyroid peroxidase antibodies in predicting the development of hypothyroidism during IFN treatment. It has been suggested that thyroid-stimulating hormone, free T4, and thyroperoxidase antibodies should be evaluated prior to initiation of IFN treatment for $\mathrm{HCV}^{81,82}$ Thyroid-stimulating hormone levels should be ideally checked every 2-3 months during treatment. If hypothyroidism develops, levothyroxine may be necessary but can be typically discontinued after completion of IFN therapy. ${ }^{83}$

\section{Conclusions}

Depression is a relatively frequent and potentially serious complication of IFN therapy for HCV infection; however, other etiologies of depression may coexist and have to be carefully excluded. Since depressed patients can suffer from longer disability periods, lower quality of life, have potentially more inpatient and outpatient visits, and increased suicide risk, early detection and treatment of depression is very important. This can be challenging if the mood changes, appetite loss, sleep disturbances, fatigue, and other vegetative symptoms are falsely attributed to the illness itself or perceived as "normal." ${ }^{\text {" }}$ Multiple screening tools are available for identifying patients at high risk for depression prior to treatment and for monitoring of the neuropsychiatric behavior of patients during IFN therapy. A history of drug abuse or major depression prior to therapy should not necessarily render patients inappropriate for IFN treatment. The use of SSRIs initiated 2-3 weeks prior to IFN treatment has been associated with fewer episodes of major depression and a higher rate of compliance to treatment with less dropout rates, even in patients who had previously failed to complete IFN treatment due to the development of severe depression. Nonetheless, their prophylactic role has not been firmly established and their use may be more appropriate therapeutically, whenever the depressive symptoms appear during HCV treatment. These and related agents, such as SNRIs, have been shown to ameliorate depressive symptoms in patients on IFN therapy. The fact that SSRIs sometimes are not efficacious, especially in a prophylactic role, can probably be explained by the fact that IFN not only increases serotonin re-uptake but also decreases serotonin synthesis. ${ }^{85}$ Overall, more studies are needed to establish the role of SSRIs and SNRIs in the prevention and treatment of depression and their 
effectiveness in compliance and SVR rates. Psychiatric evaluation is mandatory when suicidal ideation becomes evident and treatment should be discontinued in such cases. Finally, neuropsychiatric symptoms can be exacerbated by the adverse effect of IFN therapy on the thyroid. Monitoring of thyroid function should be performed in all patients prior to therapy and ideally every $2-3$ months during IFN treatment.

\section{Disclosure}

The authors declare that this paper has not been published previously in whole or part. Also, there are no financial or other competing interests.

\section{References}

1. Alter MJ, Kruszon-Moran D, Nainan OV, et al. The prevalence of hepatitis C virus infection in the United States. 1988-1994. N Engl J Med. 1999;341(8):556-562.

2. World Health Organization. Hepatitis C Fact Sheet. 2011. Available from: http://www.who.int/mediacentre/factsheets/fs164/en/. Accessed February 8, 2012.

3. Pestka S, Krause CD, Walter MR. Interferons, interferon-like cytokines, and their receptors. Immunol Rev. 2004;202:8-32.

4. Kotenko SV, Gallagher G, Baurin VV, et al. IFN-lambdas mediate antiviral protection through a distinct class II cytokine receptor complex. Nat Immunol. 2003;4(1):69-77.

5. Sheppard P, Kindsvogel W, Xu W, et al. IL-28, IL-29 and their class II cytokine receptor IL-28R. Nat Immunol. 2003;4(1):63-68.

6. Turnbull AV, Rivier CL. Regulation of the hypothalamic-pituitaryadrenal axis by cytokines: actions and mechanisms of action. Physiol Rev. 1999;79(1):1-71.

7. Kiecolt-Glacer JK, Glacer R. Depression and immune function: central pathways to morbidity and mortality. J Psychosom Res. 2002; 53(4):873-876.

8. Leonard BE. The immune system, depression and the action of antidepressants. Prog Neuropsychopharmacol Biol Psychiatry. 2001; 25(4):757-780.

9. Cooney JM, Dinan TG. Type II (glucocorticoid) receptors mediate fast-feedback inhibition of the hypothalamic-pituitary-adrenal axis in man. Life Sci. 1996;59(23):1981-1988.

10. Ramamoorthy S, Ramamoorthy JD, Prasad PD, et al. Regulation of the human serotonin transporter by interleukin 1-beta. Biochem Biophys Res Commun. 1995;216(2):560-567.

11. Abe S, Hori T, Suzuki T, et al. Effects of chronic administration of interferon alpha A/D on serotonergic receptors in rat brain. Neurochem Res. 1999;24(3):359-363.

12. Kugaya A, Kagaya A, Uchitomi Y, et al. Effect of interferon-alpha on DOI-induced wet-dog shakes in rats. JNeural Transm. 1996;103(8-9): 947-955.

13. Fujigaki S, Saito K, Sekikawa K, et al. Lipopolysaccharide induction of indoleamine 2,3-dioxygenase is mediated dominantly by an interferon- $\gamma$ independent mechanism. Eur J Immunol. 2001;31(8): 2313-2318.

14. Lotrich FE, Ferrell RE, Rabinovitz M, Pollock BG. Risk for depression during interferon-alpha treatment is affected by the serotonin transport polymorphism. Biol Psychiatry. 2009;65(4):344-348.

15. Bonaccorso S, Marino V, Puzella A, et al. Increased depressive ratings in patients with hepatitis $\mathrm{C}$ receiving interferon alpha based immunotherapy are related to interferon alpha induced changes in the serotonergic system. J Clin Psycopharmacol. 2002;22(1): 86-90.
16. Maes M, Verkerk R, Bonaccorso S, et al. Depressive and anxiety symptoms in the early puerperium are related to increased degradation of tryptophan into kynurenine, a phenomenon which is related to immune activation. Life Sci. 2002;71(16):1837.

17. Wu HQ, Guidetti P, Goodman JH, et al. Kynurenergic manipulations influence excitatory synaptic function and excitotoxic vulnerability in the rat hippocampus in vivo. Neuroscience. 2000;97(2):243-251.

18. Okuda S, Nishiyama N, Saito H, Katsuki H. 3-hydroxykynurenine, an endogenous oxidative stress generator, causes neuronal cell death with apoptotic features and region selectivity. $J$ Neurochem. 1998;70(1):299-307.

19. Orlikov AB, Prakhye IB, Ryzov IV, et al. Kynurenine in blood, plasma and DST in patients with endogenous anxiety and endogenous depression. Biol Psychiatry. 1994;36(2):97-102.

20. Mangoni A. The "kynurenine shunt" and depression. Adv Biochem Psychopharmacol. 1974;11(0):293-298.

21. Issa F, Kirch DG, Gerhardt GA, et al. A multidimensional approach to analysis of cerebrospinal fluid biogenic amines in schizophrenia: II. Correlations with psychopathology. Psychiatry Res. 1994; 52(3):251-258.

22. Maes M, Meltzer H. The serotonin hypothesis of major depression. In: Bloom FE, Kupfer DJ, editors. Psychopharmacology. New York, NY: Raven Press; 1995:933-944.

23. McIntyre N. Familial LCAT deficiency and fish eye disease. J Inherit Metab Dis. 1988;11 Suppl 1:45-56.

24. Van der Vliet A, Bast A. Effects of oxidative stress on receptors and signal transmission. Chem Biol Interact. 1992;85(2-3):95-116.

25. Bilici M, Efe H, Köroglu MA, et al. Antioxidative enzyme activities and lipid peroxidation in major depression: alterations by antidepressant treatments. J Affect Disord. 2001;64(1):43-51.

26. Maes M, Bonaccorso S, Marino V, et al. Treatment with interferonalpha of hepatitis $\mathrm{C}$ patients induces lower serum dipeptidyl peptidase IV activity, which is related to IFN alpha-induced depressive and anxiety symptoms and immune activation. Mol Psychiatry. 2001;6(4):475-480.

27. Comai S, Cavalletto L, Chemello L, et al. Effects of Peg-interferon alpha plus ribavirin on tryptophan metabolism in patients with chronic hepatitis C. Pharmacol Res. 2011;63(1):85-92.

28. Zignego MC, Cozzi A, Carpenedo R, etal. HCV patients, psychopathology and tryptophan metabolism: analysis of the effects of pegylated interferon plus ribavirin treatment. Dig Liver Dis. 2007;39 Suppl 1: S107-S111.

29. Sockalingam S, Links PS, Abbey SE. Suicide risk in hepatitis C and during interferon-alpha therapy: a review and clinical update. J Viral Hepat. 2011;18(3):153-160.

30. Rasenack J, Zeuzem S, Feinman VS, et al. Peginterferon alpha-2a improves HR-QOL outcomes compared with unmodified interferon alpha-2a in patients with chronic hepatitis C. Pharmacoeconomics. 2003;21(5):341-349.

31. Siebert U, Sroczynski G, Rossol S, et al. Cost effectiveness of peginterferon alpha- $2 \mathrm{~b}$ plus ribavirin versus interferon alpha-2b plus ribavirin for initial treatment of chronic hepatitis C. Gut. 2003;52(3): 425-432.

32. Kraus MR, Schafer A, Csef H, Scheurlen M. Psychiatric side effects of pegylated interferon alpha- $2 \mathrm{~b}$ as compared to conventional interferon alpha-2b in patients with chronic hepatitis C. World J Gastroenterol. 2005:11(12):1769-1774.

33. Fried MW, Shiffman ML, Reddy RK, et al. Peginterferon alfa-2a plus ribavirin for chronic hepatitis C virus infection. $N$ Engl J Med. 2002;347(13):975-982.

34. Manns MP, McHutchison JG, Gordon SC, et al. Peginterferon alfa-2b plus ribavirin compared with interferon alfa-2b plus ribavirin for initial treatment of chronic hepatitis C: a randomized trial. Lancet. 2001;358(9286):958-965.

35. Yasuda S, Miyata K. Interferon alfacon-1(Advaferon): a novel synthetic interferon for the treatment of hepatitis $\mathrm{C}$, its pharmacological and clinical profile. Nippon Yakurigaku Zasshi. 2002;120(6):421-426. 
36. Yao GB, Fu XX, Tian GS, et al. A multicenter, randomized, controlled trial of interferon alfacon-1 compared with alpha-2a-interferon in Chinese patients with chronic hepatitis C virus infection. J Gastroenterol Hepatol. 2000;15(10):1165-1170.

37. Melian EB, Plosker GL. Interferon alfacon-1: a review of its pharmacology and therapeutic efficacy in the treatment of chronic hepatitis $\mathrm{C}$. Drugs. 2001:61(11):1661-1691.

38. Sjogren MH, Sjorgen R, Lyons MF, et al. Antiviral response to of HCV genotype -1 to consensus interferon and ribavirin, compared to pegylated interferon and ribavirin. Dig Dis Sci. 2007;52(6):1540-1547.

39. Zacks S, Beavers K, Theodore D, et al. Social stigmatization and hepatitis C virus infection. J Clin Gastroenterol. 2006;40(3):220-224.

40. Hilsabeck RC, Malek-Ahmadi P. Neurobehavioral correlates of chronic hepatitis C. J Psychopathol Behav Assess. 2004;26:203-210.

41. Evon DM, Simpson KM, Esserman D, et al. Barriers to accessing care in patients with chronic hepatitis C: the impact of depression. Aliment Pharmacol Ther. 2010;32(9):1163-1173.

42. Randolff LS. The CES-D scale: a self-report depression scale for research in the general population. Applied Psycological Measurement. 1977;1:385-401.

43. Clark CH, Mahoney JS, Clark DJ, et al. Screening for depression in a hepatitis $\mathrm{C}$ population: the reliability and validity of the Center for Epidemiologic Studies Depression Scale (CES-D). J Advanced Nurs. 2002;40(3):361-369.

44. Phillips FH, Prebis M, Grumbeck C, et al. Effects of recognizing depression with a standardized questionnaire (CES-D) versus patient reporting of depression after a single-standardized question on the outcomes of treatment for hepatitis $C$ with pegylated interferon- $\alpha-2 b$ and ribavirin. Eur J Gastroenterol Hepatol. 2010;22(12):1435-1442.

45. Tanaka Y, Nagaki M, Tomita E, et al. Psychoneurological symptoms during interferon therapy in patients with chronic hepatitis: prospective study on predictive use of Cornell Medical Index and electroencephalogram. Liver Int. 2004;24(5):407-412.

46. Hauser P, Khosla J, Aurora H, et al. A prospective study of the incidence and open-label treatment of interferon-induced major depressive disorder in patients with hepatitis C. Mol Psychiatry. 2002;7(9):942-947.

47. Neri S, Bertino G, Petralia A, at al. A multidisciplinary therapeutic approach for reducing the risk of psychiatric side effects in patients with chronic hepatitis $\mathrm{C}$ treated with pegylated interferon $\alpha$ and ribavirin. J Clin Gastroenterol. 2010;44(9):210-217.

48. Fontana RJ, Kronfol Z, Lindsay KL, et al. Changes in mood states and biomarkers during peginterferon and ribavirin treatment of chronic hepatitis C. Am J Gastroenterol. 2008;103(11):2766-2775.

49. Kronfol Z, Litman HJ, Back-Madruga C, et al. No increase in depression with low-dose maintenance peginterferon in prior non-responders with chronic hepatitis C. J Affect Disord. 2011;129(1-3):205-212.

50. Leutscher PD, Lagging M, Buhl MR. Evaluation of depression as a risk factor for treatment failure in chronic hepatitis C. Hepatology. 2010;52(2):430-435.

51. Evon D, Ramcharran D, Belle SH, Terrault NA, Fontana RJ, Fried MW. Prospective analysis of depression during peginterferon and ribavirin therapy of chronic hepatitis C: results of the Virahep-C study. Am J Gastroenterol. 2009:104(12):2949-2958.

52. Ge D, Fellay J, Thompson AJ, et al. Genetic variation in IL28B predicts hepatitis C treatment-induced viral clearance. Nature. 2009;461(7262):399-401

53. Lotrich FE, Loftis JM, Ferrell RE, et al. IL28B polymorphism is associated with both side effects and clearance of hepatitis $\mathrm{C}$ during interferonalpha therapy. J Interferon Cytokine Res. 2011;31(3):331-336.

54. Kristiansen MG, Lochen ML, Gutteberg TJ, et al. Total and cause specific mortality rates in a prospective study of community-acquired hepatitis $\mathrm{C}$ virus infection in northern Norway. $J$ Viral Hepat. 2011;18(4):237-244.

55. Ademmer K, Beutel M, Bretzel R, et al. Suicidal ideation with IFN- $\alpha$ and ribavirin in a patient with hepatitis C. Psychosomatics. 2001; 42(4):365-367.
56. Sockalingan S, Balderson K. Major depressive episode with psychotic features induced by pegylated interferon alpha- $2 b$ and ribavirin treatment. Int Clin Psycopharmacol. 2005;20(5):289-290.

57. Dieperink E, Ho SB, Tetrick L, Thuras P, Dua K, Willenbring M. Suicidal ideation during interferon-a2b and ribavirin treatment of patients with chronic hepatitis C. Gen Hosp Psychiatry. 2004;26(3):237-240.

58. Alvarez-Uria G, Day JN, Nasir AJ, et al. Factors associated with treatment failure of patients with psychiatric disease and injecting drug users in the treatment of genotype 2 or 3 hepatitis $\mathrm{C}$ chronic infection. Liver Int. 2009;29(7):1051-1055.

59. Kraus MR, Schäfer A, Scheurlen M. Paroxetine for the prevention of depression induced by interferon alpha. N Engl J Med. 2001;345(5): 375-376.

60. Gleason OC, Yates WR, Isbell MD, Philipsen MA. An open-label trial of citalopram for major depression in patients with hepatitis C. J Clin Psychiatry. 2002;63(3):194-198.

61. Kraus MR, Schafer A, Schottker K, et al. Therapy of interferon-induced depression in chronic hepatitis $\mathrm{C}$ with citalopram: a randomized, doubleblind, placebo-controlled study. Gut. 2007;57(4):531-536.

62. Morasco BJ, Loftis JM, Indest DW, et al. Prophylactic antidepressant treatment in patients with hepatitis $\mathrm{C}$ on antiviral therapy: a doubleblind, placebo-controlled trial. Psychosomatics. 2010;51(5):401-408.

63. Musselman DL, Lawson DH, Gumnick JF, et al. Paroxetine for the prevention of depression induced by high dose interferon alpha. $N E n g l$ J Med. 2001;344(13):961-966.

64. Raison CL, Woolwine BJ, Demetrashvili MF. Paroxetine for prevention of depressive symptoms induced by interferon-alpha and ribavirin for hepatitis C. Aliment Pharmacol Ther. 2007;25(10):1163-1174.

65. Raison CL, Demetrashvili M, Carupon L, Miller AH. Neuropsychiatric adverse effects of interferon-alpha: recognition and management. CNS Drugs. 2005;19(2):105-123.

66. Kraus MR, Schafer A, Faller H, et al. Psychiatric symptoms in patients with chronic hepatitis $\mathrm{C}$ receiving alpha-2b therapy. J Clin Psychiatry. 2003;64(6):708-714.

67. Kraus MR, Schafer A, Al-Taie O, Scheurlen M. Prophylactic SSRI during interferon alpha re-therapy in patients with chronic hepatitis $\mathrm{C}$ and a history of interferon-induced depression. $J$ Viral Hepat. 2005;12(1):96-100.

68. Diez-Quevedo C, Masnou H, Planas R, et al. Prophylactic treatment with escitalopram of pegylated interferon alpha-2a-induced depression in hepatitis C: a 12-week, randomized, double-blind, placebo-controlled trial. J Clin Psychiatry. 2011;72(4):522-528.

69. Yoshida K. Milnacipran in the treatment of elderly depressed patients including a case of interferon-induced depression. Int J Psych Clin Pract. 2003;7 Suppl 1:S19-S21.

70. Zdilar D, Franco-Bronson K, Buchler N, et al. Hepatitis C, interferon alpha and depression. Hepatology. 2000;31(6):1207-1211.

71. Crone C, Gabriel GM, Wise TN. Managing the neuropsychiatric side effects of interferon-based therapy for hepatitis C. Cleve Clin J Med. 2004;71 Suppl 3:S27-S32.

72. Nickel T, Sonntag A, Backmund M, et al. Depression during therapy with interferon alpha-how long should antidepressant treatment last? Pharmacopsychiatry. 2005;38(2):102-104.

73. Lotrich F. Management of psychiatric disease in hepatitis $\mathrm{C}$ treatment candidates. Curr Hepat Rep. 2010;9(2):113-118.

74. Rifflet H, Vuillemin E, Oberti F, et al. Suicidal impulses in patients with chronic viral hepatitis $\mathrm{C}$ during or after therapy with interferon alpha. Gastroenterol Clin Biol. 1998;22(3):353-357.

75. Gould RA, Ball S, Kaspi SP, et al. Prevalence and correlates of anger attacks: a two site study. J Affect Disord. 1996;39(1):31-38.

76. Huckans M, Mitchell A, Pavawalla S, et al. The influence of antiviral therapy on psychiatric symptoms among patients with hepatitis $\mathrm{C}$ and schizophrenia. Antivir Ther. 2010;15(1):111-119.

77. Koh LK, Greenspan FS, Yeo PP. Interferon- $\alpha$ induced thyroid dysfunction: three clinical presentations and review of the literature. Thyroid. 1997;7(6):891-896. 
78. Prummel MF, Laurberg P. Interferon-alpha and autoimmune thyroid disease. Thyroid. 2003;13(6):547-551.

79. Watanabe U, Hashimoto E, Hisamitsu T, Obata H, Hayashi N. The risk factor for development of thyroid disease during interferon-alpha therapy for chronic hepatitis C. Am J Gastroenterol. 1994;89(3):399-403.

80. Deutsch M, Dourakis S, Manesis EK, et al. Thyroid abnormalities in chronic viral hepatitis and their relationship to interferon alpha therapy. Hepatology. 1997;26(1):206-210.

81. Costelloe SJ, Wassef N, Schulzt J, et al. Thyroid dysfunction in a UK hepatitis $C$ population treated with interferon- $\alpha$ and ribavirin combination therapy. Clin Endocrinol (Oxf). 2010;73(2):249-256.

82. Carella C, Mazziotti G, Amato G, et al. Interferon-alpha related thyroid disease: pathophysiological, epidemiological, and clinical aspects. $J$ Clin Endocrinol Metabol. 2004;89(8):3656-3661.

83. Sato K, Miyakawa M, Demura H. Reversible, extremely severe hypothyroidism in a patient with chronic hepatitis $\mathrm{C}$ treated with interferonalpha. Thyroid. 1996;6(3):249-252.

84. Rao M. Depression in the physically ill. Prim Psychiatry. 2008;15(9): 44-50.

85. Turner EH, Blackwell AD. 5-Hydroxytryptophan plus SSRIs for interferon-induced depression: synergistic mechanisms for normalizing synaptic serotonin. Med Hypotheses. 2005;65(1):138-144.

86. Quarantini LC, Bressan RA, Galvao B, et al. Incidence of psychiatric side effects during pegylated interferon retreatment in nonresponder hepatitis C virus-infected patients. Liver Int. 2007;27(8):1098-1102.

87. Schaefer M, Hinzpeter A, Mohmand A, et al. Hepatitis C treatment in "difficult to treat" psychiatric patients with pegylated interferonalpha and ribavirin: response and psychiatric side effects. Hepatology. 2007;46(4):991-998.

88. Yu ML, Dai CY, Lee LP, et al. Outcome of chronic hepatitis C patients who required early termination of pegylated interferon-alpha plus ribavirin combination therapy. Antiviral Ther. 2006;11(8):1015-1019.

89. Wichers MC, Koek GH, Robaeys G, et al. IDO and interferonalpha-induced depressive symptoms: a shift in hypothesis from tryptophan depletion to neurotoxicity. Mol Psychiatry. 2005;10(6):538-544.
90. Beratis S, Katrivanou A, Georgiou S, et al. Major depression and risk of depressive symptomatology associated with short-term and low-dose interferon-alpha treatment. J Psychosom Res. 2005;58(1):15-18.

91. Horikawa N, Yamazaki T, Izumi N, Uchihara M. Incidence and clinical course of major depression in patients with chronic hepatitis $\mathrm{C}$ undergoing interferon-alpha therapy: a prospective study. Gen Hosp Psychiatry. 2003;25(1):34-38.

92. Schaefer M, Schmidt F, Folwaczny C, et al. Adherence and mental side effects during hepatitis $\mathrm{C}$ treatment with interferon alpha and ribavirin in psychiatric risk groups. Hepatology. 2003;37(2):443-451.

93. Castera L, Zigante F, Bastie A, et al. Incidence of interferon alphainduced depression in patients with chronic hepatitis C. Hepatology. 2002;35(4):978-979.

94. Bonaccorso S, Marino V, Biondi M, et al. Depression induced by treatment with interferon-alpha in patients affected by hepatitis $\mathrm{C}$ virus. J Affect Disord. 2002;72(3):237-241.

95. Miyaoka H, Otsubo T, Kamijima K, et al. Depression from interferon therapy in patients with hepatitis C. Am J Psychiatry. 1999;156(7):1120.

96. McHutchison JG, Gordon SC, Schiff ER, et al. Interferon alpha-2b alone or in combination with ribavirin as initial treatment for chronic hepatitis C. N Eng J Med. 1998;339(21):1485-1492.

97. Davis GL, Esteban-Mur R, Rustgi V, et al. Interferon alpha-2b alone or in combination with ribavirin for the treatment of relapse of chronic hepatitis C. N Eng J Med. 1998;339(21):1493-1499.

98. Nozaki O, Takagi C, Takaoka K, et al. Psychiatric manifestations accompanying interferon therapy for patients with chronic hepatitis C: an overview of cases in Japan. Psychiatry Clin Neurosci. 1997;51(4):175-180.

99. Fattovich G, Giustina G, Favarato S, Ruol A. A survey of adverse events in 11,241 patients with chronic viral hepatitis treated with alpha interferon. J Hepatol. 1996;24(1):38-47.

100. Janssen HL, Brouwer JT, van der Mast RC, Schalm SW. Suicide associated with alpha-interferon therapy for chronic viral hepatitis. J Hepatol. 1994;21(2):241-243.

\section{Publish your work in this journal}

The International Journal of Interferon, Cytokine and Mediator Research is an international, peer-reviewed, open-access, online journal. The focus of the journal is to publish original research, reports, editorials, reviews and commentaries on all aspects of interferon, cytokine and mediators of inflammation from labora- tory science to therapeutic indications and clinical studies. The manuscript management system is completely online and includes a very quick and fair peer-review system, which is all easy to use. Visit http://www.dovepress.com/testimonials.php to read real quotes from published authors. 